\title{
The Impact of Work Time on Work Family Conflicts: A Study of Nurses in a Leading Hospital in Central Province Sri Lanka
}

\author{
H. M. S. V. Silva ${ }^{1}$ and D.M.K.M.K.Dissanayake ${ }^{2}$ \\ ${ }^{1,2}$ Department of Human Resource Management, University of Kelaniya, Sri Lanka \\ E-mail: ${ }^{1}$ michellevindya@kln.ac.lk, ${ }^{2}$ Kdissanayake1991@gmail.com
}

Received: June 28, 2017 Accepted: July 23, 2017 Online published: August 15, 2017

doi:10.5296/jpag.v7i3.11706

URL: https://doi.org/10.5296/jpag.v7i3.11706

\begin{abstract}
The main purpose of the study was to identify whether work time impact on work family conflicts of nurses in a leading hospital of central province in Sri Lanka. It is generally accepted that work Schedules including shift work, night shifts, unpredictable hours, and long number of working hours constitute major work related conflicts based on Role theory and JD-R theory. Thus, problem of this study is to identify the impact of work time on work family conflicts of nurses in central province of Sri Lanka. The study was quantitative and a cross-sectional survey design was followed. Data was collected through a structured questionnaire. Convenience sampling technique was applied to select the sample, and the final sample consisted of 144 nurses from a leading hospital in central province. The data was analyzed using the computer based statistical data analysis package, SPSS(Statistical Package for Social Science)English version 20 and Correlation and Regression analysis used as analytical tools. Findings of the study revealed that there is an impact from work time on work family conflicts. Further the dimensions of the work time, Number of working hours and Work schedule impact on work family conflicts of nurses in the selected hospital in central province. It was concluded that there is a positive impact of work time on work family conflicts of nurses. Further, this study supported the managers of apparel firm to get strategic steps to increase organizational effectiveness of their organizations. Nurses are to be provided with greater choice in the number and times of shifts to be worked, with local management oversight to ensure fairness and equity in shift allocation across life stages. Traditional shift hours and patterns and work starting and finishing times should be systematically reviewed, and where necessary and feasible, adjusted to provide a better fit between work, childcare and school hours.
\end{abstract}

Keywords: Work family conflicts, Work time, Nurses, Work Schedule, Working Hours 


\section{Introduction}

Over the past twenty years, researchers have made valiant attempts to understand work family conflict by examining the antecedents and consequences of the WFC. Past research examining these antecedents and consequences has purported that work-family conflict has deleterious consequences such as lowered job and life satisfaction, increased job and life stress, lowered organizational commitment, and increased intention to turnover (Allen, Herst, Bruck\& Sutton, 2000; Major, Klein \& Ehrhart, 2002).Moreover due to the antecedents such as time, Strain and behavioral based antecedents were affect to occurs the WFC. Using the establishment of these relationships as a foundation, researchers attempted to further explain the nature of work family conflict by suggesting several potential models and concepts. (Bedeian, Burke, \& Moffit, 1988; Carlson \& Kacmar, 2000; Frone, M.R., Russel, M., \& Cooper, M.L., 1992; Frone, Yardley, \& Markel, 1997; Major et al., 2002; Netemeyer, Brashear-Alejandro, \& Boles, 2004).

Yang ,Chen, Choi and Zou, (2000) define work family conflict as pressures arising from excessive workloads and typical work place time pressures such as rush jobs and deadlines. Eby, Casper, Lockwood, Bordeaux, and Brinley (2005) indicated that different paradigms or theories have been used to conceptualize or explain the inter play between work and family roles. The theories include spillover, compensation and segmentation. Rotondo and Kincaid (2008) indicated that there is a broad need for companies to address conflict through fundamental changes in work policies, job design and family support to remain competitive in the market for labor. Thus, organizational support is a vital element for the balancing act of work and family.

Further Kahn, Wolfe, Quinn, Snoek and Rosenthal (1964) suggested that work-family conflict occurs when demands from work and family are mutually incompatible to some degree. Work-family conflict has been conceptualized by Greenhaus and Beutell (1985) on the basis of source of conflict. They divided work-family conflict into three types of conflict, namely, time-based, strain-based and behavior-based conflicts. Time-based conflict refers to the participate in the other role. According to the Casper, Martin, Buffardi and Erdwins (2002) one of the conflict styles is work-family conflict, a conflict structure that involves role pressure due to incompatibility between some work and family areas. Such a conflict shows an imbalance between work and family roles. This situation occurs when the requirements of these different roles are incompatible with each other. Greenhaus and Beutell (1985) asserted that work-family conflict takes place when the time allotted to meet the needs of a role, the pressure created by a role, and the specific behaviors required for a role make it difficult to meet the needs of another one. It is, therefore, inevitable that the consequential conflict yields negative outcomes for both the individuals and the organizations. The work-family conflict is considered to be bi-directional (Frone et al., 1992). In other words, work can interfere with the family (work-to-family-conflict) and the family can interfere with work (family-to-work conflict). In addition, a meta-analysis review (Byron, 2005) found that the FWC and the WFC should be distinguished because they have unique antecedents. Thus, the majority of research on this topic examines both directions of conflict. 
Time is a limited quantity and the more time that is expended on work, the less that is available for home and family. For the most part, many Americans are thought to suffer from a "time bind", where by the hours that workers spend at work have a negative impact on their non-work lives (Hochschild, 1997). Many researchers have long held that as the number of hours an individual spends on work increases, conflict between the individual's work and home lives increases as well, and that these negative effects extend to other work and life outcomes. This is in keeping with the scarcity hypothesis which suggests that the more roles one occupies, and the more one's time is divided between those roles, the less that will be available for any specific role (Barnett \& Gareis, 2000). Logically, as time spent on work increases and time available for home and family decreases, work-family conflict (WFC) will increase. Further, as DiRenzo, Greenhaus, and Weer (2011) noted, increased working hours may also result in increasing interference between work and family responsibilities, thus resulting in family-work conflict (FWC). According to Buck, Lee, MacDermid and Smith (2000), the notion of time-based work family conflicts is derived from the scarcity model which suggests that human energy is in limited quantity.Time spent on activities within one role generally cannot be devoted to activities within another role. Consequently, an employee whose work role interferes with their family role cannot satisfy both roles in the same time period (Pleck, Staines \& Lang, 1980). Those employees spending larger amount of time at work will have less time for family roles, consequently creating conflict. Likewise, it might be expected that more time the employees work, the more likely they may find family issues such as care for children, older relatives, or the responsibilities interfere with work.

Work-family conflict is positively related to the number of hours worked per week (Burke \& Bradshaw, 1980; Pleck, Staines \& Lang, 1980) as well as the number of hours worked commuted per week (Bohen \& Viveros-Long, 1981). Moreover Skinner and Pocock ( 2008) deliberately described long hours as a risk factor for, rather than an absolute determinant of, work-life conflict. Logically, as time spent on work increases and time available for home and family decreases, work-family conflict will increase. Further, as Direnzo, Greenhaus, and Weer (2011) noted, increased working hours may also result in increasing interference between work and family responsibilities, thus resulting in family-work conflict. Work-family conflict also has been associated with the amount and frequency of overtime and the presence and irregularity of shift work (Pleck et al., 1980).

While this literature consistently finds relationships between schedule control and work-family conflict and fit, it relies almost entirely on cross-sectional data (Jansen \& colleagues, 2004). Higher-status workers likely have more economic resources, fewer family demands, and more family resources. All of these circumstances may minimize work-family conflict and create work-family fit. On the other hand, higher-status workers are likely to work long hours and to be highly engaged in their work circumstances that may increase work-family conflict and reduce work-family fit.For many human resource practitioners, increasing employee control over their work scheduling may be a central strategy to reduce employees' work-life conflict, and it is certainly one of the most common strategies utilized in Australian organizations (De Cieri, Holmes, Kelly\& Moen 2007) and in European companies. Further, these negative effects on family life seem to correlate with the length and the irregularity of the working schedule. In 
addition, one study noted that family functioning was poorer when both parents worked nonstandard hours, compared to the situation where this applied for only one or neither of the parents. The purpose of this study is to examine the impact of Work Time on Work Family Conflicts of nurses in a leading hospital in Central Province of Sri Lanka. In order to achieve above purpose, researcher has developed four hypotheses with the aid of literature as follows.

\section{H1: There is an influence from Work time on work-family conflicts.}

H1a: There is an influence from number of work hours on work family conflicts.

H1b: There is an influence from work schedule on work family conflicts.

Based on above four hypotheses, the conceptual framework of the study is as follows.

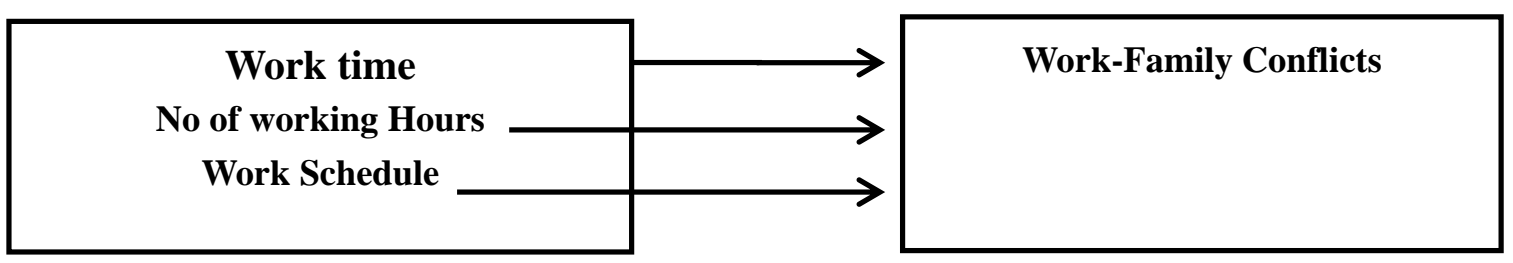

Figure 1. Relationships between Work time and Work Family Conflicts.

\section{Methods and Material}

As the research context, researcher has selected a leading hospital in central province, Sri Lanka for the study because the nurses are the persons who are with more responsibilities \& they are with the work family conflicts due to the nature of their duties \& job. They have to work longer hour of work. Sometimes the time devoted to their personal matters was not sufficient \& role conflicts are arising. So researcher identified the nurses in the selected hospital are with the work family conflicts due to the work of time. Although the study is a deductive approach and adopts survey research method, a self-administered questionnaire was chosen as data collection instrument. To measure the independent variable work time researcher had used the measurement scale developed by Carlson, Kacmar, \& Williams (1998). Dimension of the Work time, Number of work hours and work schedule were measured with a single item, reported in demographic part with hours per week and Nature of Shift work. The dependent variable, work family conflict was measured by the 16-item scale developed by the Bohen and Long (1981). In addition, pilot test was conducted prior to the distribution of the final version of the questionnaire to target population and respondents were assured that all responses of them would be strictly anonymous and encouraged them to answer the questions as truthfully as possible. The convenience sampling method was used for the study. In the study 175 questioners were distributed received only 152.144 questionnaires were usable. Response rate is $86 \%$.

\section{Data Analyses and Presentation}

\subsection{Demographic Information}


According to the sample of the study among 144 samples 14 were male and 130 were female respondents so majority of the study sample was the female nurses which are male $9.7 \%$ and female $90.3 \%$ of the total respectively. According to selected sample there were $1 \%$ of single respondents, $90 \%$ of married respondents and $6 \%$ of widow nurses and divorced nurses were $3 \%$. Majority of the sample was married nurses. Age of the respondents was grouped into four levels ranging from 20 years to over 60 years. $4 \%$ of the respondents were between $20-30$ years. $40 \%$ of the respondents were between $30-40$ years. $51 \%$ of the respondents were between $40-50$ years while $5 \%$ of respondents were between $50-60$ years. In the sample there were respondents who have the children between $1-2$ nearly $24 \%, 66 \%$ of respondents are having between 3-4 of children and having more than 4 children for $9 \%$ respondents. $64 \%$ of respondents had dependents and $36 \%$ of respondents were not having dependents. Level of experience of the respondents was grouped into five levels ranging from the below 1 years to over 10 years. So no respondents were below 1 year. $23 \%$ of respondents were between 1-5 years. $62 \%$ of respondents were both category of between $6-10$ years and $10 \&$ above were $15 \%$ of the respondents. When consider the no of working hours that respondent used to work $3 \%$ of respondents were used to work 35 or less than 35 hours, $10 \%$ were worked between $36-45$ hours, $65 \%$ of respondents were worked between 45-60 hours per week and $22 \%$ were worked more than 60 hours per week. Further $11 \%$ of respondents had not any OT hours. Between 25-30 OT hours worked by 7\% respondents. $23 \%$ respondents were worked 35-40 OT working hours. $40-45$ hours worked by $40 \%$ and more than 45 OT hours worked by $19 \%$ respondents. When analyze the nature of shift work of respondents $9 \%$ and $1 \%$ respectively worked as morning shifts and evening shifts. $3 \%$ worked night shifts. $26 \%$ respondents were worked as rotate shift basis and further $60 \%$ worked several shifts continuously.

\subsection{Peliminary Analyses}

According to field (2009) he declared that when sample size is greater than 30, data set is approximately normal. Since there are 144 cases in the study we can assume that this data set is approximately normal. Further According to when the Skewness is lower than 3 and kurtosis value is lower than 10 the data set is considered as approximately normal.when consider the linearity of the data set is checked by the scatter plot diagram. So According to the Scatter plot diagram and visual inspection the data set is linear. The linearity is 0.295 . Validity refers to the degree to which an instrument measures what is supposed to be measuring (Polit \& Hungler, 1989). The selected standard questionnaire provides a sufficient number of items that represent each variable. So in this research the researcher has used Standard Questioner for the study validity is ensured.

Reliability refers to the degree to which an instrument measure accurately. The reliability of a measure indicates the extent of stability and consistency across time and across the various items in the instrument (Polit \& Hungler, 1989). So Reliability Analysis refers to the ability of the survey instrument to produce the same results under the same conditions. To be reliable the survey instrument must be valid. 
Table 1. Reliability Statistics

\begin{tabular}{|c|c|c|}
\hline & Cronbach's Alpha & $\mathrm{N}$ of Items \\
\hline Work Family Conflicts & .728 & 16 \\
\hline Work Time & .816 & 5 \\
\hline
\end{tabular}

Source: Survey Data

\subsection{Hypothesis Testing}

Multiple regression analysis was performed to test the hypotheses of this study. The first, linear regression was performed to test the Impact of work time on work family conflicts of nurses at a leading hospital in central province in Sri Lanka.

Table 2. Correlation between work time and work family conflicts

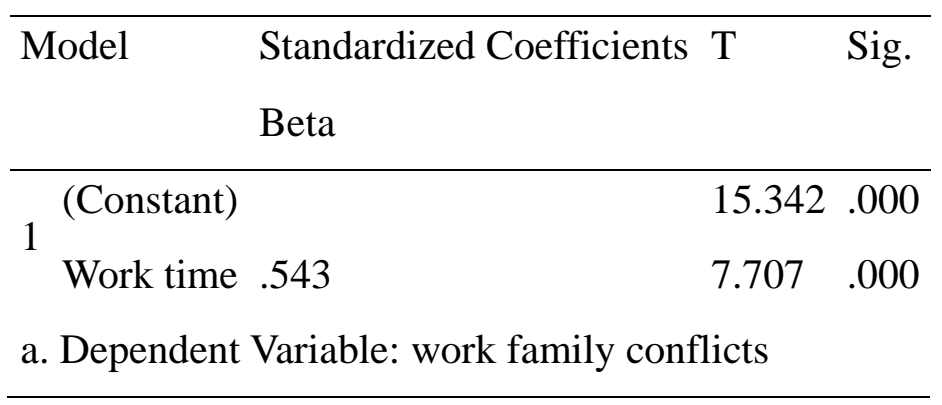

Source: Survey Data

Table 5.5 Model Summary

\begin{tabular}{|c|c|c|c|}
\hline \multirow[t]{2}{*}{ Model Adjusted R Square } & Change Statistics & & \\
\hline & R Square Change & F Change & Sig. F Change \\
\hline .290 & .295 & 59.391 & .000 \\
\hline
\end{tabular}

a. Predictors: (Constant), work time

Source: Survey Data

\subsection{Model Parameters}

According to Field (2009) the b values give the contribution of each predictor to the model. The standardized beta $(\beta)$ for work time indicates if the effect of the control variable is held constant, there is a positive impact from work time on work family conflicts among nurses, and the degree it affects work family conflicts of nurses is.543.It means that when work time of nurses increase by one standard deviation work family conflict among nurses increase by .543 standard deviations when total tenure of them is held constant. In addition, the probability of the $t$-statistic (7.70) for the standardized beta $(\beta)$ coefficient of work time is significant at .00 which is less than the level of .05.tha $t$ value is a larger value of 7.07 it depict a fair value for the study. 
3.5 Testing Sub Hypothesis

Table 3. One- way ANOVA

\begin{tabular}{|c|c|c|c|c|c|}
\hline & Sum of Squares & Df & Mean Square & $\mathrm{F}$ & Sig. \\
\hline Between Groups & 4.922 & 4 & 1.231 & 16.655 & .000 \\
\hline Within Groups & 10.270 & 139 & .074 & & \\
\hline Total & 15.193 & 143 & & & \\
\hline
\end{tabular}

Source: Survey Data

According to the table 3 , the significant value of work schedule and work family conflicts are .000 . It is less than $0.05(.000<0.05)$. It denoted that there is significant impact between work schedule and work family conflicts. Therefore, H1a hypothesis was accepted.

Table 4. One -way ANOVA

\begin{tabular}{cccccr}
\hline & Sum of Squares & Df & Mean Square & F & Sig. \\
\hline Between Groups & 6.409 & 3 & 2.136 & 34.055 & .000 \\
Within Groups & 8.783 & 140 & .063 & & \\
Total & 15.193 & 143 & & & \\
\hline
\end{tabular}

Source: Survey Data

According to the table 4, the significant value of no of work hours and work family conflicts are .000 . It is less than $0.05(.000<0.05)$. It denoted that there is significant impact between No of work hours and work family conflicts. Therefore, H1b hypothesis was accepted.

\section{Limitations of the Study}

When consider the limitation of the present study, Difficult to access to the survey population is a limitation of the study that researcher had identified when conducting the research. So it affects to reduce the sample size of the study. Further the risk of response bias also a limitation of this study. People become neutral when answering the questions. So it's difficult for the researcher to take the research decisions by using those data. Normally in a study that tests the impact of a variable to another, researcher should conduct a longitudinal study. In this study researcher implemented one shot study. In the same time, to collect data researcher used only nurses as the respondent group. Similarly researcher used only the questionnaire method to collect data for the study.

\section{Directions for the Future Research}

Recent literature has pointed out the need for research that examines the effect of organizational support on the work-family conflict. Eby et al. (2005) noted that it is particularly surprising that so few studies have examined family-supportive organizational policies, given practitioners' interest in developing "family-friendly" work environments. Grzywacz et al. (2006) recommended future research to examine the effectiveness of organizational interventions designed to help nurses balance the demands of work and family. 
Another neglected factor is organizational support for work issues. There is some evidence that employees of organizations that have programs designed to assist them in the workplace adjust better and experience fewer conflict between work and family (Grant-Vallone and Ensher, 2001). However, few studies have examined this concept in depth.

Current study attempted to measure the impact of work time on work family conflicts among nurses in a leading hospital in central province of Sri Lanka. These research findings are under limited scope and sample. This research was consisting only 144 nurses and also selected geographical area central province for the study. For the future researches, the sample of the study can be increase and data can be Collect Island wide. Further future researcher can used the several data collection methods such as interview method instead of questioner. Furthermore future researcher can conduct a research on research areas on other antecedents of work family conflicts such as strain based conflicts, behavioral conflicts. Similarly future researchers can address the managerial support to avoid the conflicts, flex time arrangements to avoid work family conflicts, effect of control variables to work family conflicts.

\section{Conclusion}

In this study researcher investigated the impact of work time on work family conflicts. So work time was the independent variable and work family conflict was the dependent variable of the study. Work time is with two dimension number of work hours and work schedules. In the study researcher examine the impact of these independent variables and dimensions on WFC. According to the research findings researcher revealed that these three variables have a significant impact on WFC. So when practicing the policies managers and other decision making parties should consider maintaining a fair work time and flexible schedule control to minimize the work family conflicts among employees in organizations.

\section{Reference}

Allen, T. D., Herst, D. E. L., Bruck, C. S., \& Sutton, M. (2000). Consequences associated with work-to-family conflict: A review and agenda for future research. Journal of Occupational Health Psychology, 5, 278-308. https://doi.org/10.1037/1076-8998.5.2.278

Barnett, R. C., \& Hyde, J. S. (2001), Women, men, work, and family: An expansionist theory. American Psychologist, 56, 781-796. https://doi.org/10.1037/0003-066X.56.10.781

Bedeian, A. G., Burke, B. G., \& Moffett, R. G. (1988), Outcomes of work-family conflict among married male and female professionals. Journal of Management, 14, 475 - 492. https://doi.org/10.1177/014920638801400310

Bohen, H. H., \&Viveros-Long, A. (1981). Balancing jobs and family life. Temple University Press.

Buck, M. L., Lee, M. D., MacDermid, S. M., \& Smith, S. (2000). Reduced load work and the experience of time among professionals and managers: Implications for personal and organizational life. In C. Cooper and D. Rousseau (Eds.), Trends in Organizational Behavior, 7: 13-36. Toronto: John Wiley \& Sons. 
Byron, K. (2005). A meta-analytic review of work-family conflict and its antecedents. Journal of Vocational Behavior, 67(2), 169-98. https://doi.org/10.1016/j.jvb.2004.08.009

Carlson, D. S., \&Kacmar, M. K. (2000). Work-family conflict in the organization: Do life role values make a difference? Journal of Management, 26, 1031-1054. https://doi.org/10.1177/014920630002600502

Casper, W. J., Martin, J. A., Buffardi, L. C., \&Erdwins, C. J. (2002). Work-family conflict, perceived organizational support, and organizational commitment among employed mothers. Journal of Occupational Health Psychology, 7, 99-108. https://doi.org/10.1037/1076-8998.7.2.99

De Cieri, H., Holmes, B., Abbott, J., \& Pettit, T. (2005). Achievements and challenges for work/life balance strategies in Australian organizations. International Journal of Human Resource Management, 16(1), 90-103. https://doi.org/10.1080/0958519042000295966

DiRenzo, M. S., Greenhaus, J. H., \& Weer, C. H. (2011). Job level, demands, and resources as antecedents of work-family conflict. Journal of Vocational Behavior, 78, 305-314. https://doi.org/10.1016/j.jvb.2010.10.002

Eby, L. T., Casper, W. J., Lockwood, A., Bordeaux, C., \& Brinley, A. (2005). Work and family research in IO/OB: Content analysis and review of the literature (1980-2002). Journal of vocational behavior, 66(1), 124-197. https://doi.org/10.1016/j.jvb.2003.11.003

Frone, M. R., Yardley, J. K., \& Markel, K. S. (1997). Developing and testing and integrative model of the work-family interface. Journal of Vocational Behavior, 50, 145-167. https://doi.org/10.1006/jvbe.1996.1577

Frone, M. R., Russel, M., \& Cooper, M. L. (1992). Prevalence of work-family conflict: Are work and family boundaries asymmetrically permeable. Journal of Organizational Behavior, 13(7), 723-729. https://doi.org/10.1002/job.4030130708.

Grant-Vallone, E. J., \& Ensher, E. A. (2001). An examination of work and personal life conflict, organizational support, and employee health among international expatriates. International Journal of Intercultural Relations, 25, 261-78.https://doi.org/10.1016/S0147-1767(01)00003-7

Greenhaus, J. H., \& Beutell, N. J. (1985). Sources of conflict between work and family roles. Academy of Management Review, 10(1), 76-88.

Grzywacz, J. G., \& Marks, N. F. (2000). Re-conceptualizing the work-family interface: an ecological perspective on the correlates of positive and negative spillover between work and family. Journal of Occupational Health Psychology, 5(1), 111-26. https://doi.org/10.1037/1076-8998.5.1.111

Hochschild, A. R. (1997). The time bind. New York: Holt and Company.

Jansen, N. W. H., Kant, I. J., Nijhius, F. J. N., Swaen, G. M. H., \& Kristensen, T. S. (2004). Impact of worktime arrangements on work-home interference among Dutch employees. 
Scandinavian Journal of Work Environment and Health, 30(2), 139-148. https://doi.org/10.5271/sjweh.771

Kahn, R. L., \& Byosserie, P. (1992). Stress in organizations, in Dunette, M.D. and Hough, L.M. (Eds), Handbook of Industrial and Organizational Psychology, Vol. 3, Consulting psychologists press, palo Alto,CA,592.

Major, V. S., Klein, K. J., \& Ehrhart, M. G. (2002). Work time, work interference with family, and psychological distress. Journal of Applied Psychology, 87, 427-436. https://doi.org/10.1037/0021-9010.87.3.427

Netemeyer, R. G., Brashear-Alejandro, T., \& Boles, J. S. (2004). A cross-national model of job related outcomes of work-role and family role variables: A retail sales context. Journal of the Academy of Marketing Science, 32, 49-60. https://doi.org/10.1177/0092070303259128

Pleck, J. H., Staines, G. L., \& Lang, L. (1980), Conflicts between work and family life. Monthly Labor Review, 103(3), 29-32.

Pocock, B., Skinner, N., \& Williams, P. (2007). Work, life and time: The Australian Work and Life Index 2007. Adelaide: Centre for Work + Life, University of South Australia. Study of employees' concerns. Journal of Family Issues, 27(3), 415-36.

Polit, D., \& Hungler, B. P. (1993). Nursing Research. Essentials of nursing research: Methods, appraisal, and utilization. 3rd edition, Lippincott Philadelphia P148.

Rotondo, D. M., \& Kincaid, J. F. (2008). Conflict, facilitation, and individual coping styles across the work and family domains. Journal of Managerial Psychology, 23(5), 484-506. https://doi.org/10.1108/02683940810884504

Yang, N., Chen, C. C., Choi, J., \& Zou, Y. (2000). Source of work-family conflict: a SINO-US comparison of the effects of work and family demands. Academy of Management Journal, 43(1), 113-123. https://doi.org/10.2307/1556390

\section{Copyright Disclaimer}

Copyright for this article is retained by the author(s), with first publication rights granted to the journal.

This is an open-access article distributed under the terms and conditions of the Creative Commons Attribution license (http://creativecommons.org/licenses/by/4.0/). 